Harvard Data Science Review • Issue 3.1, Winter 2021

\title{
Why Tennis Is Still Not \\ Ready to Play Moneyball
}

\section{Stephanie Kovalchik ${ }^{1,2}$}

${ }^{1}$ Institute for Health and Sport, Victoria University, Melbourne, Australia,

${ }^{2}$ Game Intelligence Group, Tennis Australia, Melbourne, Australia

Published on: Jan 29, 2021

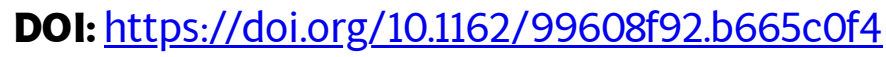

License: Creative Commons Attribution 4.0 International License (CC-BY 4.0). 
Column Editor's Note: Despite the long history of statistical methods applied to the game of tennis, the current state of analytical work seems to lag behind most professional sports. Stephanie Kovalchik explores reasons data-driven methods in tennis have not caught on, and anticipates how tennis may eventually join the data science revolution.

Keywords: sports analytics, tracking data, history, racquet sports

Since Michael Lewis's book and the Brad Pitt film Moneyball brought the sabermetric revolution into popular culture, Major League Baseball (MLB) has been the trendsetter in data and statistical innovation in sport. Baseball's latest advance is the introduction of a new tracking system, operated by Hawk-Eye Innovations, that will provide improved capture of ball and player positional data starting in the abbreviated 2020 season (Kagan, 2020). The news that the Hawk-Eye system is the latest analytics gadget for professional baseball may come as a curious development to tennis fans, where Hawk-Eye has been in operation at top professional events since 2006 (Tennis Industry_Magazine,2006). Despite having a considerable head start with a multicamera tracking system and the wealth of spatiotemporal data it produces, the use of analytics in tennis remains leagues behind professional team sports (Thomas et al.,_2017).

If Moneyball is the quintessential underdog story for modern sport, tennis may be the ultimate story of missed opportunity. To understand why analytics have yet to enter tennis's mainstream, we must trace the history of quantitative study of the game and the structural changes to professional competition that coincided with it. What emerges is a cautionary lesson of the way a sport can stymie statistical innovation when it allows data to become a tightly guarded commodity whose owners aren't invested in the understanding or improvement of sport performance.

\section{A Brief History of Statistical Thinking in Tennis}

Outsiders have been central to statistical developments in every sport. The dabbling of baseball outsiders are what turned a 19th-century English cricket reporter into the 'Father’ of America’s pastime (대iff, 2008) and what allowed a night guard at a pork and beans factory to write the cornerstone texts for a burgeoning sabermetric society (Sherer, 2017). The first hero of quantitative thinking in tennis is no less surprising.

Bruce S. Old had hardly picked up a racquet before his college years when a chance assignment at the University of North Carolina put him in the same dorm room with one of the rising stars of American tennis in the 1930s, Bryan “Bitsy” Grant, Jr. (이, 1993). Old’s primary pursuit was science, but, in attending Grant’s matches in his leisure time, he developed a fascination with tennis and was soon analyzing the game from a scientific view. After graduate school at MIT and a storied period of service in the Navy during the Second World War, Old returned home to Concord, Massachusetts, with a renewed interest in the game of tennis. In the early 1950s, to his disbelief, no public library on the East Coast had a single book on tennis tactics; so he set 
out to write his own. Four years of attending hundreds of competitive matches and applying his own shot-level charting system to live points produced notebooks filled with the first summaries of serve, return, and rally performance for a representative population of elite players.

Old shared his notebooks with a number of top doubles players of that era. But Bill Talbert was the only one to appreciate their value and agree to a partnership. By 1956, the pair secured a publishing deal, and The Game of

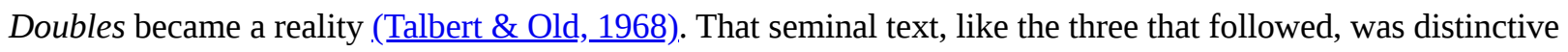
in its extensive use of tactical diagrams and path-breaking statistical tables that included the earliest examples of strategically focused metrics, like the shot potency factor reproduced in table VI (Talbert \& Old, 1968). Old had all the makings to be the Henry Chadwick or Bill James of tennis, yet few of today's professional tennis coaches or players are even aware of this one-time statistical pioneer of their sport. As a result, modern tactical instruction puts more value on opinion than evidence (ㅂited States Tennis Association [USTA], 1996).

\section{TABLE VI}

FAst Courts

Relative Probability of Winning a Point with a Given Type of Stroke Considering the Frequency of the Stroke Utilized

\section{Stroke}

Overhead

Ground stroke at net

Later volley

Lob

Passing shot

First service

First volley

Return of service

Second service

\section{Potency}

Factor

3.9

2.6

2.4

1.9

1.3

1.2

1.2

1.1

1 (basis of comparison)

Figure 1. Reproduced table from The Game of Doubles, table VI, p. 31.

Like so many missed opportunities in the history of innovation, Old's ideas were a casualty of bad timing. As Old was advancing tennis analysis, tennis was in the middle of a crisis over the professionalization of the sport. Before 1968, the four most prestigious tennis championships, known as the Grand Slams, were closed to players who competed for money (Gillmeister, 2017). After World War II, a growing number of top players 
wanted to make a career out of tennis. Shunned by the sport's governing institutions, these 'professional' players were left to compete in a ragtag set of independent exhibition circuits. If open lines of communication

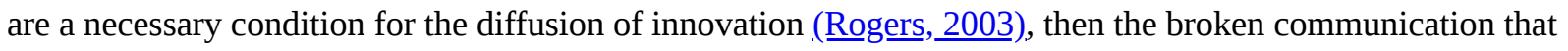
characterized the pre-Open era made it an especially difficult period for Old's ideas to take hold.

The first years after tennis's professionalization opened the door for the adoption of computerized rankings and the introduction of statistical summaries into tennis broadcasting (Scanlon et al.,2014). Still, the most interesting quantitative work of the period was not taking place within the sport but in the pages of academic journals. Kemeny \& Snell (1960) and Hsi \& Burych (1971). provided two of the earliest examples of probabilistic models for outcomes in tennis, both representing a tennis game as the outcome of independent trials of a server with a fixed win probability. Among tennis researchers, this is now commonly referred to as the 'iid model' and its analytical simplicity helped make it a bedrock for future mathematical studies in tennis. By 1974, Carter and Crews were already applying the iid model to examine the impact of the tiebreaker on the outcome and duration of matches (ㅁarter \& Crews, 1974), a hot-button issue to this day (Kovalchik \& Ingram, 2018). While Carter and Crews's analysis showed that a tiebreak could effectively reduce the duration of sets with a small impact on the chance of an upset, the advantage format continued to be played at all Grand Slams except the U.S. Open until 2019.

Probabilistic models of tennis were also beginning to be used to evaluate strategy. One of the earliest examples was an examination of optimal service strategy by S.L. (George, 1973). This work showed that the expected point value of a standard two-service strategy could be formalized as the weighted sum of winning a point on a strong serve and a weak serve, each weighted by the probability that the serve was played and was good.

George went on to contrast this expectation with alternative strategies using different combinations of risk. The simple probabilistic framework revealed a large region in which a strategy using two strong serves outperformed the status quo, making it the first scholarly work in the statistical sciences that tennis players could use to gain a competitive advantage.

Other work of the period provided an early example of an advanced metric for tennis. The development came about when Morris (1977) posed the following question: "What are the most important points in tennis?" In answer, Morris proposed a probabilistic definition that equated a point's importance to the change in match win probability if the current point was won versus lost. Using the probabilistic groundwork made in the early 1970s, he estimated point importance for a variety of scorelines and confirmed that points in tennis are not equally important. Morris further showed that the importance distribution in competitive matches was extremely right-skewed, implying that match outcomes were statistically determined by a small percentage of points. 


\section{Tennis's Second Wave of Statistical Research}

Two decades after the initial mathematical studies of the 1970s, tennis experienced a relative explosion in statistical research. At the forefront of this new wave were Franc Klaassen, a one-time national junior player for the Netherlands who entered the economics doctoral program at the University of Tilburg in 1995, and Jan Magnus, a Tilburg professor. They formed a research partnership that has spanned decades. In their earliest tennis papers, Klaassen and Magnus applied quantitative analysis to a number of "tennis myths" that had never been tested scientifically (Magnus \& Klaassen, 1996). In the process, they revisited the iid model in greater depth than any study had done before. By 2001, the duo had tested the validity of the model against outcomes from 90,000 points played at Wimbledon, the first example of a large-scale statistical analysis in tennis (Klaassen \& Magnus, 2001).

Throughout two decades of research into the statistical aspects of tennis, prediction was a predominant theme. Using a paired comparison framework, Klaassen and Magnus were the first to use model-based approaches to predict the most likely winner of points in tennis matches and to examine contextual factors that might influence a player's win probability. In doing so, they advanced tennis prediction beyond the mathematical models of the 1970s and made the fitting of statistical models to large samples of competitive data the new standard. Extensions soon followed as more researchers sought to measure and test predictors of tennis outcomes and create more sophisticated models of tennis performance (Kovalchik, 2016).

\section{A Fractured Data Landscape}

By the 2000s, there was a growing body of statistical research on tennis. Yet that research made it clear that tennis had a data problem. George's 1973 work on service strategies explicitly pointed to the challenges of data collection in tennis: "Unfortunately, none of the major lawn tennis associations routinely collect the detailed data on service which is needed for an examination of service strategy” (George, 1973). More than three decades later, despite the growth in computing and data management tools, data availability remained a significant barrier to tennis researchers. When Barnett \& Clarke (2005) proposed a service model adjusted for opponent skill, they demonstrated their method with data from a single Australian Open match, a sample size that was well within the norms of contemporary analyses.

While the tabulation of statistics has been a fixture of baseball since the first box score appeared in 1845, the organizers of tennis competitions have failed to quantify their sport for most of its history. Significant barriers to the collection and distribution of statistics are ongoing and are a direct consequence of the decentralized structure that emerged from tennis's political battles of the 1970s. For a sport that is most recognized for its dogged commitment to individualism, it is perhaps not a coincidence that it has arrived at an organizational structure that is so fractured. The fragmentation begins with the multiple promoters of tennis events - the International Tennis Federation, the Grand Slam Board, the ATP Tour, and WTA — and continues with the way 
in which these promoters contract with players and tournament directors, treating all involved as independent actors who are left to vie for their own survival (Gibson, 2010).

These Darwinian organizational characteristics have ramifications for every aspect of the sport, including its data collection and sharing. Players have the most to benefit from rigorous performance analysis, but tournaments are the gatekeepers of performance data. Not only are events not beholden to the interests of players, their interests are often in conflict, as players are the greatest cost to an event's profits. This means that decisions about data collection and sharing do not aim to improve performance but to improve business (Sorrentini \& Pianese,2011). The consequences of these economic incentives are evident in the highly aggregated match summary data that events have put in the public domain as a result of sponsorship deals with information technology companies like IBM and Infosys, who provide tennis tournaments with digital products in exchange for significant branding opportunities. In their aim to attract fans and create brand awareness, these digital partners may create opportunities for analysis, but only coincidentally. A statistician who wanted to work with the entirety of the data collected at top professional events would have the difficult task of convincing 108 separate tournaments that this research investment was in their interest.

\section{Will Tennis's Analytics Revolution Ever Come?}

After several questionable line calls marred Serena Williams's pursuit of the 2004 U.S. Open title, the USTA launched a concerted effort to bring electronic line-calling to tennis. Just two years later, the U.S. Open was the first major event to debut the Hawk-Eye player challenge system: a multi-camera tracking system for line-call review. It was a pivotal move for tennis, as it put the sport at the forefront of innovations in officiating. Being one of the first adopters of a positional tracking system was also an opportunity for tennis to compete with the major leagues in the big data race in sport. That chance quickly passed when Hawk-Eye signed away the rights to its data. In the hands of tournament organizers, for whom detailed performance data has no immediate value, tennis tracking data, which includes information about the position of the ball and players throughout a tennis match, has resulted in little more than descriptive summaries of what can be easily observed (Kovalchik \& Reid, 2019).

Tennis still has a chance to join the Moneyball era of sports, but it will require a radical change to the structural barriers that have historically kept the highest quality tennis data out of the reach of the players and coaches, who could benefit the most from their analysis. That change could come from within, if, for instance, players were to organize and demand rights to competitive data. The recent announcement of the Professional Tennis Players Association, an effort to form a union of professional tennis players led by world No. 1-ranked Novak

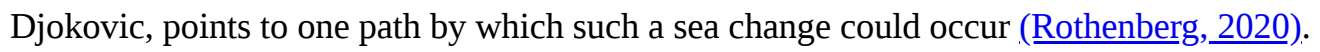

History suggests that the solution to tennis's data problem is more likely to come from the outside. When the major leagues denied fans access to play-by-play data in the 1980s, a group of number-hungry baseball enthusiasts organized an effort, known as Project Scoresheet, to compile an independent database on their own. 
Today, owing to the dedication of many volunteers, public statistics exist for nearly every play ever made in professional baseball. These steps were pivotal not only for the early growth of the Society for American Baseball Research, but also for the early adoption of statistical thinking by baseball insiders.

The lessons from baseball's data history have not been lost on tennis enthusiasts. In fact, Jeff Sackmann, one of the most recognized promoters of tennis data analysis in the past decade, got his start working on baseball statistics. After creating a data aggregation tool for college baseball in 2007, Sackmann applied his webscraping and programming skills to launch the tennisabstract.com site, which remains the single most comprehensive public database of match results and summary statistics for tennis matches played in the Open era. By 2015, Sackmann founded the Match Charting Project (MCP), a crowd-sourcing effort that aims to be tennis's analog to baseball's Retrosheet. The MCP gives volunteer tennis coders a system for charting every shot of a tennis match, watched live or from a video recording, and contributing qualitative description of shots to a central database, which includes 8,026 total matches at the time of this writing.

The establishment of the MCP has been a major advance for tennis researchers, but the information collected can still not compete with the richness and timeliness of the data captured by tennis's current tracking systems. Summary data can be useful for identifying trends and setting expectations about broad outcomes in a tennis match. However, without the spatial and temporal characteristics of ball and player movement, it will be impossible to examine the causes of these outcomes, which limits the relevance of crowd-sourced data for tennis stakeholders. A small but growing number of tennis research papers in the field of computer vision point to the possibility of using machine learning to close the information gap that exists between public and proprietary tennis data (Zhang et al.,2020). Such a solution would bring tennis analytics full circle, calling on the most cutting-edge of data science methods to address the sport's analytics deficit.

Sports wanting to spur on their own Moneyball era should take stock from tennis's story. Despite the trove of data that tennis possesses, its analytics revolution has never come because it has not done more to remove the obstacles that stand between the data and the players and coaches who have the greatest interest in their analysis. Although the business decisions that have created these obstacles won't be easy to undo, a solution from tennis outsiders may still be on the horizon. Continued advances made by data scientists in the analysis and modeling of sports broadcast video may just be the answer tennis needs to usher it into a new era of statistical thinking.

\section{Disclosure Statement}

Stephanie Kovalchik has no financial or non-financial disclosures to share for this article. 


\section{References}

Barnett, T., \& Clarke, S. R. (2005). Combining player statistics to predict outcomes of tennis matches. IMA Journal of Management Mathematics, 16(2), 113-120. https://doi.org/10.1093/imaman/dpi001

Carter, W. H., \& Crews, S. L. (1974). An analysis of the game of tennis. The American Statistician, 28(4), 130134. https://amstat.tandfonline.com/doi/abs/10.1080/00031305.1974.10479094

George, S. (1973). Optimal strategy in tennis: A simple probabilistic model. Journal of the Royal Statistical Society: Series C, 22(1), 97-104. https://doi.org/10.2307/2346309

Gibson, A. D. (2010). The Association of Tennis Professionals: From player association to governing body. Journal of Applied Business \& Economics, 10(5). http://www.digitalcommons.www.nabusinesspress.com/JABE/Jabe105/GibsonWeb.pdf

Gillmeister, H. (2017). Tennis: A cultural history. Equinox Publishing Limited. https://www.google.com/books/edition/Tennis Cultural History/44Vu3DdHFvsC?

Hsi, B., \& Burych, D. (1971). Games of two players. Journal of the Royal Statistical Society: Series C, 20(1), 86-92. https://doi.org/10.2307/2346634

Kagan, D. (2020). There's lots of physics to do now that Hawk-Eye is up and running. https://tht.fangraphs.com/theres-lots-of-physics-to-do-now-that-hawk-eye-is-up-and-running/

Kemeny, J. G., \& Snell, J. L. (1960). Finite Markov chains. Van Nostrand. https://books.google.com.au/books? id=WORLAAAAMAAJ

Klaassen, F. J., \& Magnus, J. R. (2001). Are points in tennis independent and identically distributed? Evidence from a dynamic binary panel data model. Journal of the American Statistical Association, 96(454), 500-509. https://doi.org/10.1198/016214501753168217

Kovalchik, S., \& Reid, M. (2019). The Game Insight Group: A model for academic-industry partnerships for sports statistics innovation. Quality Engineering, 31(1), 23-38. https://doi.org/10.1080/08982112.2018.1519578

Kovalchik, S. A. (2016). Searching for the GOAT of tennis win prediction. Journal of Quantitative Analysis in Sports, 12(3), 127-138. https://doi.org/10.1515/jqas-2015-0059

Kovalchik, S. A., \& Ingram, M. (2018). Estimating the duration of professional tennis matches for varying formats. Journal of Quantitative Analysis in Sports, 14(1), 13-23. https://doi.org/10.1515/jqas-2017-0077

Magnus, J. R., \& Klaassen, F. J. (1996). Testing some common tennis hypotheses: Four years at Wimbledon. Center for Economic Research, Tilburg University. https://janmagnus.nl/papers/JRM042.pdf 
Morris, C. (1977). The most important points in tennis. Optimal Strategies in Sport, 1(1), 131-140.

Old, B. (1993). Dr. Bruce Old 573 Lowell Road. Concord Oral History Program.

https://concordlibrary.org/special-collections/oral-history/Old

Rogers, E. M. (2003). Diffusion of innovations (5th ed.). Free Press. https://books.google.com/books?

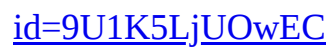

Rothenberg, B. (2020, August 28). Djokovic and other top men are creating a players'association. New York Times. https://www.nytimes.com/2020/08/28/sports/tennis/tennis-union-men-djokovic.html

Scanlon, B., Long, S., \& Long, C. (2014). Bad news for McEnroe: Blood, sweat, and backhands with John, Jimmy, Ilie, Ivan, Bjorn, and Vitas. St. Martin’s Publishing Group. https://books.google.com/books?

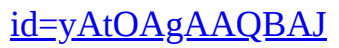

Schiff, A. J. (2008). “The Father of Baseball”: A biography of Henry Chadwick. McFarland. https://www.google.com/books/edition/The Father of Baseball/yamGHfofkuMC?

Sherer, P. D. (2017). When is it time to stop doing the same old thing? How institutional and organizational entrepreneurs changed Major League Baseball. Journal of Business Venturing, 32(4), 355-370. https://doi.org/10.1016/j.jpusvent.2017.03.001

Sorrentini, A., \& Pianese, T. (2011). The relationships among stakeholders in the organization of men's professional tennis events. Global Business and Management Research: An International Journal, 3(2), 141156. https://www.google.com/books/edition/Global Business and Management Research/mWJenUBv5KIC Talbert, W. F., \& Old, B. S. (1968). The game of doubles in tennis. Lippincott.

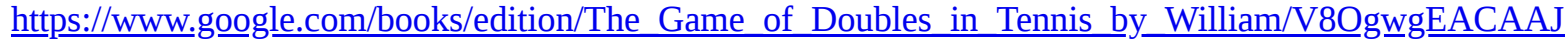

Tennis Industry Magazine. (2006, January). Instant replay debuts in pro tennis. http://www.tennisindustrymag.com/articles/2006/05/industry_news 9.html

Thomas, G., Gade, R., Moeslund, T. B., Carr, P., \& Hilton, A. (2017). Computer vision for sports: Current applications and research topics. Computer Vision and Image Understanding, 159(1), 3-18. https://doi.org/10.1016/j.cviu.2017.04.011

United States Tennis Association [USTA]. (1996). Tennis tactics: Winning patterns of play. Human Kinetics. https://www.google.com/books/edition/Tennis Tactics/UQy $\underline{X}$ urzthwC

Zhang, H., Sciutto, C., Agrawala, M., \& Fatahalian, K. (2020). Vid2Player: Controllable video sprites that behave and appear like professional tennis players. arXiv. https://doi.org/10.48550/arXiv.2008.04524 
(C2021 Stephanie Kovalchik. This article is licensed under a Creative Commons Attribution (CC BY 4.0) International license, except where otherwise indicated with respect to particular material included in the article.

\section{References}

- Barnett, T., \& Clarke, S. R. (2005). Combining player statistics to predict outcomes of tennis matches. IMA Journal of Management Mathematics, 16(2), 113-120. https://academic.oup.com/imaman/articleabstract/16/2/113/704903

- Carter, W. H., \& Crews, S. L. (1974). An analysis of the game of tennis. The American Statistician, 28(4), 130-134. https://amstat.tandfonline.com/doi/abs/10.1080/00031305.1974.10479094?

- George, S. (1973). Optimal strategy in tennis: A simple probabilistic model. Journal of the Royal Statistical Society: Series C (Applied Statistics), 22(1), 97-104.

https://rss.onlinelibrary.wiley.com/doi/abs/10.2307/2346309

- Gibson, A. D. (2010). The Association of Tennis Professionals: From player association to governing body. Journal of Applied Business \& Economics, 10(5). http://www.digitalcommons.www.nabusinesspress.com/JABE/Jabe105/GibsonWeb.pdf $€$

- Gillmeister, H. (2017). Tennis: A cultural history. Equinox Publishing Limited. https://www.google.com/books/edition/Tennis Cultural History/44Vu3DdHFvsC?

- Hsi, B., \& Burych, D. (1971). Games of two players. Journal of the Royal Statistical Society: Series C (Applied Statistics), 20(1), 86-92. https://rss.onlinelibrary.wiley.com/doi/abs/10.2307/2346634

- Kagan, D. (2020). There's lots of physics to do now that Hawk-Eye is up and running. https://tht.fangraphs.com/theres-lots-of-physics-to-do-now-that-hawk-eye-is-up-and-running/-

- Kemeny, J. G., \& Snell, J. L. (1960). Finite Markov chains. Van Nostrand. https://books.google.com.au/books?id=WORLAAAAMAAJ $\leftrightarrows$

- Klaassen, F. J., \& Magnus, J. R. (2001). Are points in tennis independent and identically distributed? Evidence from a dynamic binary panel data model. Journal of the American Statistical Association, 96(454), 500-509. https://www.tandfonline.com/doi/abs/10.1198/016214501753168217

- Kovalchik, S. A. (2016). Searching for the GOAT of tennis win prediction. Journal of Quantitative Analysis in Sports, 12(3), 127-138. https://www.degruyter.com/view/journals/jgas/12/3/article-p127.xml

- Kovalchik, S. A., \& Ingram, M. (2018). Estimating the duration of professional tennis matches for varying formats. Journal of Quantitative Analysis in Sports, 14(1), 13-23. https://www.degruyter.com/view/journals/jgas/14/1/article-p13.xml $€$

- Kovalchik, S., \& Reid, M. (2019). The Game Insight Group: A model for academic-industry partnerships for sports statistics innovation. Quality Engineering, 31(1), 23-38. https://www.tandfonline.com/doi/abs/10.1080/08982112.2018.1519578

- Magnus, J. R., \& Klaassen, F. J. (1996). Testing some common tennis hypotheses: Four years at Wimbledon. Center for Economic Research, Tilburg University. https://janmagnus.nl/papers/JRM042.pdf $\leftrightarrows$ 
- Morris, C. (1977). The most important points in tennis. Optimal Strategies in Sport, 1(1), 131-140.

- Old, B. (1993). Dr. Bruce Old 573 Lowell Road. Concord Oral History Program. https://concordlibrary.org/special-collections/oral-history/Old $\leftrightarrows$

- Rogers, E. M. (2003). Diffusion of innovations (5th ed.). Free Press. https://books.google.com/books?

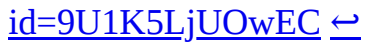

- Rothenberg, B. (2020). Djokovic and other top men are creating a players'association. New York Times. https://www.nytimes.com/2020/08/28/sports/tennis/tennis-union-men-djokovic.html

- Scanlon, B., Long, S., \& Long, C. (2014). Bad news for McEnroe: Blood, sweat, and backhands with John, Jimmy, Ilie, Ivan, Bjorn, and Vitas. St. Martin’s Publishing Group. https://books.google.com/books? $\underline{\mathrm{id}=\mathrm{yAtOA}} \underline{\underline{A A Q B A J}} \underline{\underline{B A}}$

- Schiff, A. J. (2008). “The Father of Baseball”: A biography of Henry Chadwick. McFarland. https://www.google.com/books/edition/The Father of Baseball/yamGHfofkuMC?

- Sherer, P. D. (2017). When is it time to stop doing the same old thing? How institutional and organizational entrepreneurs changed Major League Baseball. Journal of Business Venturing, 32(4), 355-370.

https://www.sciencedirect.com/science/article/abs/pii/S0883902617301684

- Sorrentini, A., \& Pianese, T. (2011). The relationships among stakeholders in the organization of men's professional tennis events. Global Business and Management Research: An International Journal, 3(2), 141156. https://www.google.com/books/edition/Global Business and Management Research/mWJenUBv5KIC

- Talbert, W. F., \& Old, B. S. (1968). The game of doubles in tennis. Lippincott. https://www.google.com/books/edition/The Game of Doubles in Tennis by_William/V8OgwgEACAAJ?

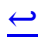

- Tennis Industry Magazine. (2006). Instant replay debuts in pro tennis. http://www.tennisindustrymag.com/articles/2006/05/industry_news 9.html $\Leftarrow$

- Thomas, G., Gade, R., Moeslund, T. B., Carr, P., \& Hilton, A. (2017). Computer vision for sports: Current applications and research topics. Computer Vision and Image Understanding, 159(1), 3-18. https://www.sciencedirect.com/science/article/abs/pii/S1077314217300711

- United States Tennis Association [USTA]. (1996). Tennis tactics: Winning patterns of play. Human Kinetics. https://www.google.com/books/edition/Tennis Tactics/UQyX urzthwC?

- Zhang, H., Sciutto, C., Agrawala, M., \& Fatahalian, K. (2020). Vid2Player: Controllable video sprites that behave and appear like professional tennis players. arXiv. https://arxiv.org/abs/2008.04524 